\title{
DEBATES
}

\section{Condiciones de surgimento de las organizaciones armadas de izquierda durante los años 1960-1970 en Argentina}

\section{The left-wing armed organization origin conditions during the years 1960-1970 in Argentina}

\section{Marco Iazzetta}

\section{Resumen}

El presente trabajo tiene por objeto analizar las condiciones de surgimiento de las organizaciones armadas de izquierda durante los años 1960-1970 en Argentina. Para ello, primeramente abordaremos las condiciones políticas que motivaron la violencia reactiva popular y ulteriormente la violencia racionalizada de las organizaciones guerrilleras de la época. En segundo lugar, nos referiremos a los condicionantes socioeconómicos que habrían motivado el surgimiento de estas organizaciones, interrogándonos si la Argentina se encontraba verdaderamente bajo una profunda crisis económica o si esta apreciación era una mera justificación para iniciar la lucha armada. Por último, analizaremos algunas realizaciones artísticas producidas en estos años, entendiendo que constituyen una vía privilegiada para comprender la penetración capilar que tuvo el proyecto revolucionario de estas organizaciones y la legitimidad que alcanzó la utilización de la violencia para intervenir en política.

\section{Palabras clave}

Lucha Armada; Argentina; Guerrilla.

\begin{abstract}
This paper aims to analyze the conditions that paved the way for left-wing armed organizations during the 1960's and 1970's in Argentina. To achieve this goal, firstly, we will discuss the political conditions that triggered the popular reactive violence and subsequently the rationalized violence led by the guerilla organizations of the time. Secondly, we will discuss the socioeconomic determinants that could have motivated the origins of these organizations; and we will talk about whether Argentina was actually undergoing a deep economic crisis or if this point of view worked as a way to justify the origins of the armed struggle. At last, we will analyze some artistic productions developed during these years, having in mind that they can help understanding the assimilation that the revolutionary armed project of these organizations had and the use of violence's legitimacy to intervene in politics.
\end{abstract}

\section{Keywords}

Armed Struggle; Argentina; Guerrilla. 


\section{Introducción}

Desde fines de los años 1960, la Argentina se vio sacudida por una violencia generalizada, donde varias autodenominadas "agencias de seguridad pública", grupos guerrilleros y bandas organizadas por sectores sindicales y empresariales se enfrentaron entre sí y asesinaron a mucha gente indefensa (véase O'DONNELL, 1997, p. 151-152). En ese escenario confuso y tumultuoso atravesado por la violencia, diversas organizaciones guerrilleras se convirtieron en actores fundamentales.

Los años 1960-1970 en Argentina forman parte de la "década larga" (JAMESON, 1997, p. 66), inaugurada en América Latina con el triunfo de la Revolución cubana y clausurada en Argentina con el Golpe de Estado de 1976. Constituye un período controvertido que continúa despertando diferentes sensaciones, pues habrá quienes recordarán con dolor la violencia de aquellos años, el aventurismo político y la fantasía voluntarista de muchos de sus protagonistas. Otros, en cambio, podrán destacar la carga de generosidad, idealismo y desinterés por los bienes materiales que marcó a la militancia setentista (TCACH, 2003). Es por ello que estos años aún despiertan un fuerte interés, cuestión que queda puesta de manifiesto a partir de la presencia que tiene el tema en los debates públicos de nuestros días como también por la voluminosa literatura periodística y la creciente producción académica que intenta descifrar las claves de ese traumático momento.

El presente trabajo tiene por objeto analizar las condiciones de surgimiento de las organizaciones armadas de izquierda durante los años 1960-1970 en Argentina. Para ello, primeramente abordaremos aquellos rasgos que hacen a la singularidad de este período (la centralidad de la política, la "nueva estructura de sensibilidad", la convicción de la posibilidad de una transformación radical de las estructuras y la inevitabilidad de la revolución socialista, la radicalización de la juventud etc.), para posteriormente centrarnos en las condiciones políticas que favorecieron la aparición de la violencia reactiva característica de las grandes movilizaciones del período (como el $\operatorname{Cordobazo}^{1}$ ); y ulteriormente de la violencia racionalizada de las organizaciones guerrilleras de la época.

En segundo lugar, nos referiremos a los condicionantes socioeconómicos que habrían motivado el surgimiento de estas organizaciones, interrogándonos si la

\footnotetext{
${ }^{1}$ Se conoce como Cordobazo a un importante movimiento de protesta ocurrido en la ciudad de Córdoba el 29 de mayo de 1969. Su consecuencia más inmediata fue la caída del gobierno de Juan Carlos Onganía.
} 
Argentina se encontraba verdaderamente bajo una profunda crisis económica, o si esta apreciación era una mera justificación para iniciar la lucha armada.

Por último, analizaremos algunas realizaciones artísticas producidas en estos ańos, entendiendo que constituyen una vía privilegiada para comprender la penetración capilar que tuvo el proyecto revolucionario de estas organizaciones y la legitimidad que alcanzó la utilización de la violencia para intervenir en política.

\section{La singularidad histórica de los 1960-1970's}

Se podrían mencionar diferentes rasgos como singulares de este período. Entre ellos, probablemente uno de los más destacados es el interés por la política. De este modo, siguiendo el modelo propuesto por Albert Hirschman (1986), los años 1960 y 1970 deberían incluirse en una teoría de ciclos de comportamiento colectivo, como un ejemplo de los ciclos definidos por el interés repentino e intenso por los asuntos públicos.

Inclusive, podríamos distinguir como otra particularidad de la época al nacimiento de lo que Raymond Williams denominaría una "estructura de sentimiento" (WILLIAMS, 1997) - ideas y creencias, pero también valores, sentimientos y pasiones que definen una época - emergente en los años de la segunda posguerra. En efecto, Terán (2008) propone la existencia de cuatro almas que habitaron el período: el alma Becket del sinsentido, el alma Kennedy de la Alianza para el Progreso, el alma Lennon del flower power y el alma Che Guevara de la rebeldía revolucionaria.

Asimismo, existía la convicción de que una transformación radical, en todos los órdenes, era inminente. Como señala Gilman (2012), todos los estudiosos del período coinciden en caracterizarlo por la percepción generalizada de una modificación ineludible y deseada del universo de las instituciones, de la subjetividad, del arte y la cultura. Además, esta certeza sobre una inminente transformación de las estructuras estaba muy ligada a la creencia de la inevitabilidad de la revolución socialista, la proximidad de una victoria mundial que iba a cambiar el rostro del mundo y del hombre. Esto se debía principalmente a las expectativas que había generado la Revolución Cubana, la cual fue interpretada como la demostración evidente de que un emprendimiento de innovación radical podía triunfar a partir de un núcleo reducido de militantes que tuviera la voluntad de oponerse a un régimen autoritario. 
Por otro lado, la juventud y la cuestión generacional constituyen otra de las claves para entender a este período ${ }^{2}$. Esto era una manifestación de un proceso de modernización cultural que tuvo como actor central a las clases medias urbanas y abarcó numerosos aspectos de la vida cotidiana que incluían desde nuevos hábitos de consumo especialmente orientados al sector juvenil, así como el cuestionamiento de la moral sexual y familiar tradicional, el nuevo rol de la mujer y la divulgación del psicoanálisis, hasta aquellas dimensiones asociadas a las vanguardias y la experimentación artística (SVAMPA, 2007).

Ser joven durante los 1960 y 1970’s presuponía un valor en sí mismo y buena parte de la juventud occidental juzgó que lo heredado "apestaba a viejo", "caduco" (FERRER, 2013). En efecto, las transformaciones culturales de los ańos 1960 llevaron a los jóvenes a apoyar un cuestionamiento total de la civilización occidental y cristiana en lo que respecta tanto a la vida privada como a la vida pública. Frente a estos cambios hubo dos respuestas diferentes: la privada (hipismo) y la pública (revolución), y si bien la rebeldía social era la base en común de ambos modelos, las diferencias surgirán con respecto al tema de la política revolucionaria y la lucha armada (OLLIER, 1998).

No obstante, la sola mención de estas características (la centralidad de la política, la "nueva estructura de sensibilidad", la convicción de la posibilidad de una transformación radical de las estructuras y la inevitabilidad de la revolución socialista, la radicalización de la juventud etc.) nos brindaría un panorama acotado de los años 1970 en Argentina si no hiciéramos hincapié en su rasgo más distintivo: la utilización de la violencia como una herramienta legitima para intervenir en política.

En realidad, la violencia y el autoritarismo siempre fueron elementos constitutivos de la cultura política argentina. En este sentido, el recurso de la violencia - ya sea para destruir la sociedad existente, para mantenerla, para hacerla regresar a algún punto original del cual alguna vez se desvió - fue un lugar común durante gran parte del siglo XX tanto en el terreno de los hechos como en el de los universos ideológico-políticos (OLLIER, 1986). La simple enumeración de algunos acontecimientos de los ańos anteriores a los 1970's justifica esta afirmación: el

\footnotetext{
${ }^{2}$ Esta cuestión se ve reflejada en la literatura a partir del Diario de la Guerra del Cerdo (1999 [1969]) de Adolfo Bioy Casares, una novela que anticiparía los sucesos de los ańos posteriores. En la misma se representa a la lucha intergeneracional entre jóvenes y viejos, reflejando el endiosamiento y la soberbia característica de la juventud. Asimismo, se observa la percepción de una crisis terminal inminente, característica anteriormente mencionada a la hora de describir la década del 1970: "[... ¿ No estaremos en vísperas de una gran hecatombe? [...] ¿No es el acabose? ¿No estaremos en vísperas del fin del mundo?” (p. 124).
} 
bombardeo de la Plaza de Mayo el 16 de Junio de 1955 unos meses antes del derrocamiento de Perón, la represión sobre quienes intentaron oponerse a la ilegalidad del gobierno dictatorial, en particular los fusilamientos de José León Suarez ${ }^{3}$, la prohibición de pronunciar públicamente el nombre del líder Juan Domingo Perón, el secuestro del cadáver de su esposa "Evita", la anulación de elecciones con un resultado adverso para las fuerzas en el gobierno, la "Noche de los Bastones Largos" ${ }^{\prime}$, etc., son características de una época marcada por la violencia.

A pesar de que la violencia fue una constante en la vida política argentina, los 1970's presentarán como particularidad el hecho de reducir de forma radical los términos de la política a los de la guerra. En efecto, un capítulo nuevo de la historia de este país se iniciará entre los años 1968 y 191970 con el surgimiento de las organizaciones armadas de Nueva Izquierda (NI), particularmente, de cinco organizaciones: las Fuerzas Armadas Revolucionarias (FAR), las Fuerzas Armadas Peronistas (FAP), las Fuerzas Armadas de Liberación (FAL), los Montoneros y el Ejército Revolucionario del Pueblo (ERP), siendo este último el brazo armado del Partido Revolucionario de los Trabajadores (PRT). Algunas de estas organizaciones luego de espectaculares acciones iniciales no volverán a emerger, otras se fusionarán y así finalmente no quedarán más que dos: los Montoneros y el PRT-ERP.

\section{La "Revolución Argentina" y el Onganiato}

Después de la caída del régimen de Perón en el año 1955 su movimiento político será sistemáticamente proscripto en las subsiguientes elecciones hasta el año 1973, a partir de la intervención progresiva de las FF.AA. (Fuerzas Armadas de la República Argentina) como árbitro, estableciendo las reglas del juego político. Como consecuencia natural, todo gobierno elegido en estos comicios restringidos, será considerado ilegítimo por un amplio sector de la población que se identificaba con el peronismo, poniéndose en entredicho, a la vez, el modelo de democracia parlamentaria como marco de resolución de conflictos y como mecanismos de acceso al gobierno (HILB y LUTZKY, 1984). Esta situación se profundizará aún más con el

\footnotetext{
${ }^{3}$ Los fusilamientos de José León Suárez sucedieron el 9 de junio de 1956 durante el gobierno de facto autodenominado "Revolución Libertadora", en los basurales de la localidad José León Suárez, en el partido de General San Martín, Gran Buenos Aires. Las víctimas fueron militantes políticos, civiles y militares peronistas.

${ }^{4} \mathrm{La}$ "Noche de los Bastones Largos" se refiere al desalojo violento ocurrido el 29 de Julio de 1966, por parte de la Dirección General de Orden Urbano de la Policía Federal Argentina, de cinco facultades de la Universidad de Buenos Aires (UBA) ocupadas por estudiantes, profesores y graduados, en oposición a la decisión del gobierno militar de intervenir las universidades y anular el régimen de gobierno.
} 
Golpe de Estado de 1966, la autodenominada "Revolución Argentina", pues el congelamiento oficial de toda actividad política, la represión contra la Universidad y la censura, terminarán cerrando los canales de expresión disponibles.

Los ideólogos del golpe propusieron un programa general para detener lo que veían como la obstinada declinación del país. Sus ideas estaban influidas por las políticas y hasta el estilo del régimen militar de Brasil, que estaba en el poder desde el año 1964. Como sus pares brasileños, los promotores del golpe en Argentina sentían desprecio por las ineficiencias de las políticas parlamentarias y la aducida venalidad de los políticos civiles, que ponían los intereses individuales y partidarios por encima de los de la nación. Además, estaban decididos a romper con los obstáculos estructurales, ya fueran económicos o políticos que impedían un desarrollo capitalista exitoso y establecer el orden y la disciplina, por la fuerza si era necesario, en la inconstante vida política del país (BRENNAN, 1996).

El nuevo gobierno, amparándose en la unidad de las Fuerzas Armadas y en el apoyo de sectores liberales y sindicales, propuso como objetivos, por un lado, suspender sine die las actividades de los partidos políticos y de las instituciones parlamentarias, y por el otro, consagrar expresamente la desvinculación de las Fuerzas Armadas del gobierno disponiendo que éstas "no gobernarán ni cogobernarán”. Con esto se buscaba erradicar la denominada "partidocracia" e instaurar a Juan Carlos Onganía como una suerte de monarca autocrático ocupando la cúspide de un régimen en el que el único que haría política sería el gobierno. En otras palabras, producida la unidad (militar y social) y superado el conflicto, la política dejaría el lugar a la administración con el resultante predominio de técnicos situados por encima de los intereses sectoriales y capaces de proponer e implementar las soluciones óptimas. De igual forma, la fórmula institucional de la "Revolución Argentina" se vio rodeada por una retórica corporativista que puso el énfasis en la gradual articulación de "consejos de comunidad" encargados de canalizar las actividades de las organizaciones sociales y de servir como mecanismos consultivos y asesores de las autoridades (CAVAROZZI, 2006).

La renovación de la política argentina fue el tema central de la propuesta de Onganía, pues se partía de la convicción de que el problema del país era fundamentalmente político, y que de lo que se trataba era de barrer con la complicada, ineficiente, y eventualmente peligrosa intermediación de los circuitos partidarios, parlamentarios y corporativos para que se desplegaran plenamente las potencialidades de crecimiento económico. En este sentido, el gobierno de Onganía no sólo empleó el término "revolución" por sus connotaciones de cambio sistémico sino también en su sentido de proceso social sin límites temporales. Se suprimieron 
todas las formas de participación popular, se cerró el Congreso, se proscribieron los partidos políticos, las universidades fueron clausuradas (BRENNAN, 1996).

Como agravante de este escenario, Terán (2008) señala que el "shock autoritario" desencadenado por la dictadura tuvo también severas consecuencias en el ámbito cultural. Imbuido de una mirada autoritaria incapaz de discriminar entre el modernismo experimentalista y las actitudes políticas expresamente orientadas al cambio revolucionario, el régimen gobernante terminó por unificar lo que el autor denomina - como vimos anteriormente -, las "almas" Lennon y Guevara de los años 1960. De modo que para combatir a esta última, el régimen gobernante consideró necesario desplegar campańas contra el pelo largo, los músicos de rock, el uso de minifalda, así como también secuestrar libros, censurar y prohibir películas como $E l$ silencio de Ingmar Bergman o Blow-Up de Michelangelo Antonioni, allanar editoriales (y hoteles por hora). En particular, la intervención de las Universidades trajo aparejado un efecto destructivo a partir del extraordinario drenaje de docentes e investigadores.

Sin embargo, la pieza clave de la "Revolución Argentina" fue su programa económico que procuraba profundizar el proyecto desarrollista e insertar a la Argentina en el orden económico internacional de la posguerra mediante un continuo desarrollo industrial y una estrecha asociación con el capital multinacional. El Ministro de Economía de Onganía, Adalbert Krieger Vasena, abandonó el intento de Illia de promover la industrialización de acuerdo con lineamientos neoperonistas que promovían el mercado interno y apoyaban a los pequeños y medianos industriales que operaban en él. En su lugar, la modernización debía alcanzarse eliminando las trabas a la acumulación capitalista, reduciendo el gasto público que alimentaba las presiones inflacionarias e incrementando la productividad laboral, nada de lo que parecía posible para los planificadores civiles y militares de Onganía en el sistema político pluralista y democrático de la Argentina (BRENNAN, 1996).

Asimismo, se le pueden atribuir al gobierno de Onganía algunos éxitos políticos, aunque temporarios, pues aparte de los éxitos económicos alcanzados hasta la primera mitad de 1969 - una normalización sin costos sociales demasiados elevados, aumento de la balanza de pagos - el gobierno consiguió que: los partidos cayeron en un pozo de irrelevancia e inactividad, los sindicatos fueron forzados a aceptar sucesivamente la abolición, en la práctica, del derecho de huelga - a raíz de la sanción de la ley de arbitraje obligatorio de agosto de 1966 - y la intervención gubernamental de los gremios industriales más importantes como resultado del rotundo fracaso del "Plan de Acción" de comienzos de 1967, y que Perón fuera convirtiéndose en una especie de muerto político aparentemente despojado de todas 
las armas que había utilizado tan eficazmente entre 1955 y 1966 para desestabilizar a los gobiernos en el poder (CAVAROZZI, 2006). Paralelamente, Cavarozzi (2006) señala que se generó, aunque por un lapso, la impresión de que se estaba conformando un eficiente y armonioso sistema de decisiones en el que los protagonistas principales, y casi exclusivos, eran aquellos que ocupaban los despachos gerenciales de las grandes empresas y los cargos jerárquicos de las instituciones estatales encargadas de diseñar e implementar la política económica.

No obstante, el intento de eliminar las trincheras del juego político, clausurando los múltiples mecanismos institucionales y extra-institucionales a través de los cuales el compromiso había predominado en la sociedad y en la política argentinas y pretendiendo canalizar y "ordenar" los diversos intereses y orientaciones sociales desde un Estado supuestamente omnisciente y jerárquico, terminó por producir lo que, de alguna manera, había venido a erradicar como posibilidad en Argentina (Ibidem).

Waldmann (1982) profundiza el análisis de esta cuestión al señalar que si bien hasta el año 1966 casi todos los factores del poder político estaban dispuestos a perseguir sus objetivos de manera violenta, el desborde de la violencia había sido en general impedido por la pluralidad de los ejes de conflicto y la actitud de relativa flexibilidad y disponibilidad de las partes en conflicto. La pluralidad de los planos de conflicto, por neutralizarse mutuamente, tenían un efecto obstructor para la violencia y por ejemplo, aunque en el curso de manifestaciones contra el gobierno organizadas por los sindicatos había choques sangrientos entre trabajadores y la policía, ambas partes se esforzaban en evitar que el derramamiento de sangre llevara a una confrontación que destruyera el sistema, para no hacer el juego de grupos radicales.

La situación cambió radicalmente en 1966 con la "Revolución Argentina", pues a partir de entonces se eliminó la pluralidad de ejes de conflicto, siendo todas las confrontaciones de allí en adelante, disputas parciales dentro de la controversia política total que tenía por un lado a los militares en el poder y por otro, al resto de los factores políticos. Sin embargo, la polarización de las fuerzas políticas y sociales no se produjo inmediatamente después del Golpe de Estado, sino más bien de forma gradual. Como señalamos anteriormente, los éxitos transitorios en el campo económico al sobreponerse al estancamiento y frenar la inflación, en un principio le permitió al gobierno contar con el apoyo de la clase media alta y de la clase alta. No obstante, Waldmann (1982) señala que rápidamente fue evidente que los esfuerzos para remplazar la falta de legitimación plebiscitaria por el rendimiento económico u otras realizaciones, fracasaban porque no bastaban para hacer olvidar a los factores de poder su anterior influencia. De este modo, cada vez más partidos, asociaciones y 
demás grupos se pasaban a la oposición y hasta parte de las fuerzas armadas comenzaron a distanciársele. La polarización de los sectores ganó importancia porque no se limitaba al ámbito político-social sino que se extendía también a la esfera económica.

La consecuencia más importante de esta distribución de fuerzas e intereses era que, aunque sólo provisoriamente, fue franqueado el abismo que separaba por un lado a los grupos extremistas que tenían por objeto un cambio de sistema revolucionario y por otro a los sectores políticos moderados interesados en la conservación de las estructuras existentes. Era evidente que aquellos grupos que en principio estaban predispuestos contra un vuelco radical, no se daban, o no querían darse cuenta debido a su oposición al régimen militar, del programa real de los elementos con los que se estaban aliando. Esa flexibilidad fundamental mencionada anteriormente, que no excluía alianzas temporarias con organizaciones en extremo opuestas ideológicamente, repercutió luego en la nueva constelación política. Con la desaparición de aquellos factores que frenaban y controlaban la violencia, la aparición de una guerrilla se hizo posible (WALDMANN, 1982).

\section{La violencia se abre camino}

En este marco, la violencia se fue abriendo paso en un clima social previamente caracterizado por algunos observadores como "pacífico"s. En un primer momento, a partir de las grandes movilizaciones populares que se inauguraron con el Cordobazo, las expresiones de violencia tendrán un carácter reactivo (HILB, 2003). A la inesperada y espontánea explosión popular, que expresó, entre otras cosas, el aislamiento e ignorancia del gobierno frente a la sociedad, se sumó la renuncia de las Fuerzas Armadas a desencadenar una represión más sistemática y severa que la aplicada hasta entonces, como lo requería un Onganía que había perdido noción, asimismo, de lo que estaba ocurriendo, bajo la superficie, dentro de las instituciones militares. Además, quedaba demostrado que no era tal el "consenso tácito" ni el "ansia de autoridad" con que se había argüido el derecho a mandar sobre una población cuya inercia, luego de la alta activación anterior a 1966, se revertía ahora con una fuerza y agresividad que aquel período no había conocido. El "orden”, la "paz social" y su sustento en el "consenso tácito" habían terminado y, con estos, lo que había parecido el inmenso poder que respaldaba las políticas económicas y sociales en curso (O’DONNELL, 1982).

\footnotetext{
${ }^{5}$ Esta cuestión es mencionada por Carassai (2013, p. 64) cuando se refiere a los calificativos utilizados por algunas publicaciones de la época. En particular, se habla de "trienio de paz constructiva" y "pax revolucionaria”.
} 
Otra consecuencia fundamental fue una difundida creencia en la violencia como un medio eficiente para el logro de metas en la arena política. El carácter espontáneo del Cordobazo implicaba un acto de violencia popular que había derrotado a la policía, forzando una ardua intervención del Ejército, provocando la renuncia del equipo de Krieger Vasena, y notoriamente, socavando la cohesión interna del gobierno y de sus principales aliados. Posteriormente, este tipo de violencia dejará su lugar a otra de carácter racionalizado o instrumentalizado, que tendrá como fin la realización de la revolución. Como señala O’Donnell (1982),

Lo que en un primer momento fue audaz expresión de los agravios de un pueblo, no tardó en ser transformado en la cara monstruosa de una generalizada y creciente violencia que habría de convertirse, desde entonces [...] en una característica constitutiva de la vida cotidiana en la Argentina. A partir de entonces poco puede entenderse lo ocurrido si no se tiene en cuenta el miedo, casi siempre silenciado u oblicuamente manifestado, que permeó todas las capas de esta sociedad (O’DONNELL, 1982, p. 265).

El Cordobazo adquirió la dimensión de un mito y fue vislumbrado por las organizaciones armadas de izquierda como un acontecimiento que confirmaba el papel indispensable de la violencia en la construcción de una sociedad más justa. En el imaginario guerrillero su propia presencia se debía a un pedido y a una necesidad del pueblo y no a los anhelos, deseos, sentimientos, creencias y necesidades arraigadas en ellos mismos (OLLIER, 1986; O’DONNELL, 1982). De este modo, este acontecimiento fue considerado por las organizaciones armadas de izquierda como el esbozo, sin dirección revolucionaria, de la insurrección.

Como señala Altamirano (2011, p. 142), "captada de acuerdo con un imaginario arcaizante, la protesta daba forma sensible a una expectativa que la precedía". No se le podría haber asignado otro sentido a este episodio mientras el futuro de la sociedad argentina fuera el de la revolución socialista y mientras el camino para lograrlo fuera la guerra revolucionaria.

No obstante, a la hora de caracterizar este nuevo fenómeno, no se puede soslayar que la legitimidad política que alcanzó la violencia formaba parte de un "clima de época" mundial que inclusive terminó penetrando en los discursos de la Iglesia, pues durante el papado de Pablo VI incluso la encíclica Populorum Progressio (promulgada el 26 de marzo de 1967) aceptaba la violencia en casos de "tiranía" evidente y prolongada (GILMAN, 2012). Simultáneamente, hay que considerar, por un lado, a la Guerra Fría como marco internacional que interpretaba los sucesos 
latinoamericanos con la clave invariable del enfrentamiento de Estados Unidos y la Unión Soviética, y por el otro, a la Revolución Cubana y al guevarismo como elementos que sacudieron las tendencias pacifistas y reformistas de las izquierdas latinoamericanas, colocando el problema de la "toma del poder" en el centro del imaginario político.

Es en este contexto mundial y local en el que, por lo tanto, surgen las organizaciones armadas de izquierda argentinas. Éstas comparten el mismo discurso autojustificatorio acerca de la necesidad de la lucha armada y de que la violencia popular (o desde abajo) había sido una reacción legítima frente a la violencia opresora (o desde arriba). Se consideraba a la violencia como fundadora del orden político, social y económico en el cual descansa el conjunto de la sociedad, por lo que las organizaciones tenían como preocupación permanente desnudar la "violencia oculta" en la sociedad (OLLIER, 1986).

\section{Condicionantes de carácter socioeconómico: ¿la Argentina atravesaba una crisis económica?}

Queríamos detenernos brevemente en otra de las justificaciones que brindaron las organizaciones armadas de izquierda de la época a la hora de iniciar la lucha armada en la Argentina: la situación económica explosiva en el que se encontraba inmerso el país, con una pobreza extendida, elevados indices de subdesarrollo y los niveles de explotación de la clase trabajadora hasta extremos inhumanos. La apelación a las armas era, entonces, presentada como el único camino lógico para revertir este escenario y establecer una sociedad nueva radicalmente igualitaria.

Sin embargo, algunos autores (ARONSKIND, 2011; LOTERSZTAIN, 2010) sugieren que estas organizaciones construyeron una versión acomodaticia de la realidad argentina para legitimar sus proyectos políticos, pues toda la información histórica disponible sobre esos años sugiere que fueron extremadamente conflictivos en lo político, pero de claro progreso económico y social. Es más, cabe destacar que el período 1963-1974 se trató de una de las épocas más prósperas y equitativas de toda la historia argentina, pues el PBI aumentó ininterrumpidamente y alcanzó en los once años un notable aumento acumulado del $81 \%{ }^{6}$, e incluso desde un punto de vista comparativo el crecimiento argentino casi triplicaba al crecimiento promedio

\footnotetext{
${ }^{6}$ Lotersztain (2010), afirma que esta cifra es especialmente significativa ya que el país no venía, como había ocurrido más de una vez (y ocurriría en el futuro) de la emergencia de alguna crisis o depresión económica de inusitada gravedad y en consecuencia no se partía de un piso muy bajo como referencia de crecimiento.
} 
internacional en aquellos ańos. Otros datos para destacar serían que la participación de los asalariados en el PBI se mantuvo en un promedio del 46\% hasta 191970 , alcanzando un 48\% en 1974 (LOTERSZTAIN, 2010).

La sociedad argentina vivía procesos de transformación considerables, de la mano de la industrialización, de las mejoras en las condiciones de vida de los trabajadores y el consumo de las capas medias, del incremento del salario real, de la presencia de un Estado que expandía sus actividades y sostenía una red de protección social creciente. Como señala Aronskind (2011), si bien esa mejora progresiva en los estándares de vida, fundamentalmente de los sectores urbanos que representaban la amplia mayoría de la población, esto no implicaba que no hubiera pobreza e indigencia, aunque los niveles eran muy inferiores a los que conoció el país en los 30 ańos posteriores. La tasa de desempleo normal en aquel período se situaba entre el $3 \mathrm{y}$ el $4 \%$, y por otra parte, existían bolsones de pobreza que se concentraba geográficamente en el norte del país, y en los alrededores de las grandes urbes, que estaban viviendo un proceso de expansión y modernización.

Sin embargo, también debemos tomar en consideración a la inflación para tener un panorama económico amplio, pues entre los años 191960 y 191970 fue un problema mundial y durante el período 1963-1974 fue del 31\% en nuestro país. Estos eran niveles altos si se los compara con el pasado, pero reducidos si se tiene en cuenta los continuos valores de más del $100 \%$ que se presentaron invariablemente durante el "Proceso de Reorganización Nacional" a partir del año 1976, y los insólitos $3079 \%$ y $2314 \%$ de 1989 y 1990 (Ibidem). Es obvio que los miembros de las organizaciones armadas de izquierda no podían prever el futuro y saber de antemano que la situación económica argentina de los años venideros sería aún peor que la que del período 191970-1974. No obstante, esta cuestión pondría en evidencia que los factores económicos por sí solos no pueden explicar el surgimiento de la guerrilla en la Argentina.

De este modo, sostenemos que las organizaciones armadas de izquierda eludieron de manera deliberada estos datos económicos y sociales con el objeto de emparentar la situación de Argentina con la de países como Vietnam, Angola y China, que habían desarrollado de forma exitosa una experiencia revolucionaria o que se encontraban todavía en medio de ese proceso. Sin embargo, el caso argentino, distaba mucho de asemejarse al de estos países. Como señala Aronskind (2011), en primer lugar, éstos vivieron situaciones históricas límites, con una opresión y una violencia extremas, y sufrieron grandes descalabros tanto políticos, sociales y económicos producto de la lucha militar generalizada y la ocupación extranjera. En 
suma, el análisis de una serie de datos duros que mencionaremos a continuación nos permitirá profundizar en esta cuestión $n^{7}$ :

Tabla 1 - Indicadores del nivel de desarrollo socioeconómico al año 1962

\begin{tabular}{c|c|c|c|c}
\hline País & $\begin{array}{c}\text { PIB per capita } \\
(1962) \text { en } \\
\text { dólares de 2000 }\end{array}$ & $\begin{array}{c}\text { Expectativa de } \\
\text { vida al nacer } \\
(1962)\end{array}$ & $\begin{array}{c}\text { Tasa de } \\
\text { natalidad, por } \\
\text { cada 100 } \\
\text { personas (1962) }\end{array}$ & $\begin{array}{c}\text { Población } \\
\text { urbana como \% } \\
\text { total (1962) }\end{array}$ \\
\hline Argelia & 1433 & 48 & 5,0 & 33 \\
\hline Argentina & 5677 & 65 & 2,3 & 75 \\
\hline Cuba & 2046 & 65 & 3,4 & 59 \\
\hline China & 550 & 49 & 3,7 & 17 \\
\hline Vietnam & 855 & 45 & 4,6 & 16 \\
\hline
\end{tabular}

Fuente: Aronskind (2011).

Estos datos son indicadores del nivel de desarrollo socioeconómico que tenía la Argentina en comparación con los países que habían emprendido un proceso revolucionario exitoso. La distancia en materia de riqueza disponible por habitante es evidente; el acceso a alimentación razonable, vivienda y otros bienes de consumo característicos de las sociedades modernas por parte de la mayoría de la población argentina marcaban también una fuerte diferencia con estos países señalados típicamente como "tercermundistas". Asimismo, otro indicador interesante es la gran cantidad de población rural que se observa en estos países en comparación con la Argentina, y relacionado con esto también presentan una alta tasa de natalidad, características de las sociedades de tipo campesina, poco desarrolladas ${ }^{8}$.

En suma, una vez que las organizaciones armadas de izquierda resolvieron que para terminar con lo que consideraban una situación de explotación y de opresión semicolonial y de dependencia de la Argentina los cambios debían ser de fondo y a través de la lucha armada, tuvieron que dejar necesariamente de lado estas cifras

\footnotetext{
7 La fuente de los mismos es Aronskind (2011). Cabe destacar que en la comparación también incluimos los datos de Cuba.

${ }^{8}$ La baja tasa de natalidad, en cambio, se vincula al nivel de desarrollo económico y a las pautas de consumo y de vida que adoptan las sociedades a medida que acceden a nuevos estándares socioculturales. Ver Aronskind (2011).
} 
indicativas del nivel de desarrollo y crecimiento de la Argentina, y basarse en una imagen de la sociedad más cercana a la de aquellos países que habían impulsado de manera exitosa la revolución. El único propósito era legitimar la lucha armada.

\section{El arte como acción politica: su vinculación con el proceso de radicalización creciente ${ }^{9}$}

Otra vía de entrada para comprender el contexto particular de los años 19601970 y el clima de época que motivó el surgimiento de las organizaciones armadas de izquierda es el análisis de las diferentes realizaciones artísticas producidas en estos años. En este sentido, sostenemos que esto nos permitirá comprender de forma más acabada en qué medida la "nueva estructura de sensibilidad", la radicalización política y la legitimidad de la violencia como una herramienta para actuar en política elementos que como vimos anteriormente hacen a la singularidad histórica de este período - penetraron de forma capilar en la sociedad.

Cabe señalar particularmente que a fines de la década del 1960 cambió totalmente la percepción que se tenía del arte hasta ese momento con el surgimiento de un nuevo movimiento estético, promovido por grupo de artistas de vanguardia de Buenos Aires y de Rosario que habían protagonizado una tajante ruptura con las instituciones artísticas a las que habían estado vinculados hasta entonces (en especial, el Instituto Di Tella). El arte deviene con ellos en acción y la acción artística lleva por contacto, por deriva o consecuencia - a la acción política.

Apostaron además por involucrar el arte en el imaginario de cambio social: como motor impulsor, como ejército subordinado, como mundo ajeno a lo real, como un vector capaz de incidir en las condiciones de existencia. La vanguardia artística tenía la percepción de estar llamada a cumplir un rol protagónico en la revolución que se percibía inminente e inevitable, y pasó a entenderse a sí misma como parte de la vanguardia política e inventó su lugar en la revolución. En este sentido, se promovió una disolución de las fronteras entre acción artística y acción política: la violencia política se volvió un material estético y las prácticas, recursos y procedimientos "militantes" (el volanteo, las pintadas, el acto-relámpago, el sabotaje, el secuestro, la acción clandestina etc.) fueron apropiados como materia artística. Incluso, se realizaron copamientos, para aumentar la resonancia de una toma de posición, provocar un incidente, generar una denuncia, exacerbar una contradicción,

\footnotetext{
${ }^{9}$ Este apartado será desarrollado a partir de los aportes de Longoni y Mestman (2010) y Longoni (2014).
} 
interpelar a otros artistas y al público, llegar a los medios de prensa etc., emulando, de este modo, los procedimientos de la militancia radicalizada.

La realización más conocida de esta vanguardia fue "Tucumán Arde", el mayor intento colectivo de sostener el arriesgado camino de articulación entre experimentación artística y acción política, es decir, de encontrar un modo de contribuir eficazmente desde el arte experimental a la revolución. Su objetivo fue denunciar la gravedad de la crisis que asolaba a buena parte de la población tucumana a causa del cierre de los ingenios azucareros y la falsedad de la propaganda oficial de la dictadura de Onganía sobre el paliativo lanzado en 1966, el “Operativo Tucumán”. La dictadura de Onganía terminó clausurando la obra poco después de su inauguración en Buenos Aires, precipitando la crisis que atravesaban los colectivos de artistas, llevándolos a su disolución y, en el caso de la mayoría de sus integrantes, al abandono del arte, en algunos casos para dar lugar al pasaje a la militancia política armada, en un contexto en el que la revolución aparecía como única fuerza dadora de sentido.

Por otra parte, también podemos encontrar otros ejemplos de la estrecha vinculación existente entre arte-política-revolución-violencia durante esos años. En este sentido, el 23 de septiembre de 1972 se inauguró "Arte e ideología en CAyC al aire libre” en la Plaza Roberto Arlt, ubicada en Rivadavia y Esmeralda, en pleno centro de Buenos Aires, con una nutrida participación colectiva de sesenta artistas, además de grupos de teatro, performance y música. Entre las obras montadas podemos destacar dos de Luis Pazos: un voluminoso fardo de pasto envuelto con un gran moño de cinta rosa del que colgaba una tarjeta con el título Proyecto de solución para el problema del hambre en los paises subdesarrollados, según las grandes potencias. Y, por otro, tres lápidas negras con el título Monumento al prisionero político desaparecido, al pie de las cuales se acostaron en el piso tres jóvenes que visitaban la exposición, entrelazando las manos.

Otras dos obras aludieron directamente a la masacre de Trelew $^{10}$, la cual había ocurrido hacía un mes. Horacio Zabala presentó allí 300 metros de cinta negra para enlutar una plaza pública, una intervención que consistió en rodear las paredes lindantes de la plaza con una extensa banda de plástico negro. Por otra parte, La realidad subterránea fue una instalación que idearon y decidieron incluir a último minuto los artistas Luis Pazos, Eduardo Leonetti, Roberto Duarte Laferriere y

\footnotetext{
${ }^{10}$ La Masacre de Trelew consistió en el asesinato de 16 miembros de distintas organizaciones armadas peronistas y de izquierda, presos en el penal de Rawson, capturados tras un intento de fuga. Los sucesos tuvieron lugar en la madrugada del 22 de agosto de 1972, en la Base Aeronaval Almirante Zar, una dependencia de la Armada Argentina próxima a la ciudad de Trelew, provincia del Chubut.
} 
Ricardo Roux. Decidieron aprovechar una excavación existente en un costado de la plaza, próxima a una pared. En ese foso, al que se bajaba con dificultad por una escalera de madera, colgaron fotografías de campos de concentración nazis. Construyendo una analogía con la reciente masacre en la Argentina, en la pared superior al pozo pintaron dieciséis cruces blancas seguidas por tres puntos suspensivos, en claro homenaje a los presos políticos fusilados en la cárcel de Rawson. Debajo de las cruces, con la misma pintura blanca, escribieron el título de la intervención: La realidad subterránea.

La muestra en la plaza Roberto Arlt estaba planeada como la primera de una serie de exposiciones en espacios públicos de la ciudad de Buenos Aires, pero el proyecto quedó violentamente interrumpido apenas dos días después de la inauguración, al ser clausurada la muestra precipitadamente por la intervención policial generada por la denuncia de un funcionario municipal.

Asimismo, entre agosto y diciembre de 1973 tuvo lugar una nueva intervención colectiva que aludía directamente a la masacre de Trelew (en su primer aniversario) y a los cruentos sucesos de Ezeiza ${ }^{11}$ (ocurridos dos meses antes), y se inscribe otra vez en la estrategia de apropiarse de aquellos espacios institucionales en los que se pudiera postular una intervención política. Se trata de la convocatoria a la cuarta edición del Salón Artistas con Acrílicopaolini, un premio privado que promovía los vínculos entre la nueva industria y el arte experimental proponiendo a los artistas la adopción de acrílico como material para sus obras.

En el marco de este evento, Perla Benveniste, Juan Carlos Romero, Eduardo Leonetti, Luis Pazos y Edgardo Vigo presentaron Proceso a nuestra realidad (también recordada como Ezeiza es Trelew). Construyeron un muro, apilando los ladrillos, pegaron afiches que la organización PRT-ERP había impreso con el rostro de cada uno de los fusilados de Trelew y la consigna "Gloria a los héroes de Trelew. Castigo a los asesinos" y otro afiche del mismo estilo, diseñado por Romero, con el conocido y estremecedor fotograma tomado durante los incidentes en Ezeiza en el que se ve cómo un manifestante es alzado de los pelos violentamente desde el palco por alguien. Además, pintaron con aerosol otras dos consignas: de un lado del muro "Ezeiza es Trelew"; del otro, "Apoyo a los leales. Amasijo a los traidores". Inclusive, para incitar a que el público se apropiase del espacio, los artistas colocaron algunos

\footnotetext{
${ }^{11} \mathrm{La}$ "Masacre de Ezeiza" sucedió el 20 de junio de 1973, día en el que se congregaron miles de personas para recibir a Juan Domingo Perón después de 18 ańos en el exilio. La movilización para recibirlo en el aeropuerto de Ezeiza terminó en una masacre desatada por la derecha peronista: se considera que aproximadamente hubo 13 muertos y 365 heridos si bien las cifras nunca pudieron cotejarse por la ausencia de una investigación oficial.
} 
aerosoles de pintura en las cercanías del muro, dando cabida a nuevas pintadas e inscripciones.

\section{A modo de conclusión}

Este trabajo tuvo por objeto analizar las condiciones políticas, socioeconómicas y culturales que favorecieron el surgimiento de las organizaciones armadas de izquierda durante los años 1960-1970 en Argentina. Éstas se constituyeron en actores fundamentales en el escenario político argentino fundamentalmente a partir del año 191970 con la creación de Montoneros y el brazo armado del Partido Revolucionario de los Trabajadores (PRT), el Ejército Revolucionario del Pueblo (ERP).

En primer lugar, abordamos una serie de factores que en su conjunto habrían motivado el surgimiento de las organizaciones guerrilleras y legitimado al ejercicio de la violencia como un instrumento válido para hacer política, a saber: el interés por la política y lo público, el nacimiento de una nueva "estructura de sentimiento", la radicalización política de los jóvenes y su cuestionamiento total de la civilización occidental y cristiana en lo que respecta tanto a la vida privada como a la vida pública; la convicción de que una transformación radical, en todos los órdenes, era inminente y relacionado con esto, destacamos también la creencia en un pronto triunfo de la revolución socialista, y que esto le cambiaría el rostro al mundo y al hombre.

Asimismo, otro factor seńalado fue la crisis de la democracia originada con la caída del régimen de Perón en 1955, a partir de la proscripción de su movimiento y la intervención de las FF.AA. como árbitro que estableció las reglas del juego político. Esta situación se profundizó aún más con el Golpe de Estado de 1966 imponiendo un congelamiento de toda actividad política, la represión contra la Universidad y la censura, clausurándose por ende, los múltiples mecanismos institucionales y extrainstitucionales a través de los cuales el compromiso había predominado en la sociedad. Por lo demás, la disputa política se terminó concentrando en un antagonismo central - la oposición contra la dictadura militar -, favoreciendo a partir de la "Revolución Argentina", las acciones políticas de carácter violento.

Por otra parte, el clima de efervescencia social y de gran movilización, expresado por ejemplo en el Cordobazo, fue otro de los factores que habrían legitimado la posterior utilización de la violencia racionalizada. Este acontecimiento se convirtió en un mito y fue considerado por las organizaciones guerrilleras como el esbozo sin dirección revolucionaria de la insurrección. Al mismo tiempo, trajo aparejado la creencia de que la violencia era un medio eficiente para el logro de metas 
en la arena política, pues se había logrado derrotar a las fuerzas del orden y socavar la unidad interna del gobierno de Onganía.

Del mismo modo, demostramos que el surgimiento de las organizaciones armadas de izquierda no puede ser explicado a partir del análisis de la situación económica que estaba atravesando Argentina en ese momento. Éstas habrían construido una versión acomodaticia de la realidad para legitimar sus proyectos políticos, pues los índices económicos demuestran que los años 1960-1970’s fue uno de los períodos más prósperos y equitativos de toda la historia argentina. En suma, el país se encontraba muy alejado de la situación de crisis terminal en materia política, económica y social que habían afrontado aquellas experiencias revolucionarias triunfales, como la de Vietnam, China y Angola, que eran consideradas como modelos a seguir por la guerrilla argentina.

Por otro lado, el análisis de algunas realizaciones artísticas de la época nos permitió visualizar por un lado, la penetración capilar que tuvo el clima de época de los ańos 1960-1970 y por el otro, dar cuenta de la legitimidad que gozaban las organizaciones armadas de izquierda. La vanguardia artística rosarina y porteńa promovió una concepción del arte estrechamente vinculada con la política, el arte en sí devino en acción política, un motor de cambio, una expresión para denunciar el ejercicio de la violencia física y solapada que del Estado burgués, pero a la vez como promotora de una violencia de otro tipo, liberadora y creadora, en el marco de la revolución que estaba en ciernes.

En suma, consideramos que estos condicionantes contextuales o estructurales no pueden explicar por sí solos el surgimiento de las organizaciones armadas de izquierda. En este sentido, no debemos soslayar que la historia o el destino no forzaron a los integrantes de estas organizaciones a tomar las armas y a utilizar la violencia para intervenir en el campo político. Éstos optaron ética y políticamente por ella: hubo una voluntad revolucionaria de cambiar el mundo y el hombre. Con ello queremos sugerir que este camino no era necesariamente el único que había disponible - aunque tal vez era el más tentador - y que, por lo tanto, todos los actores que intervinieron en este período convulsionado de la historia argentina no pueden buscar excusas ni desentenderse de la responsabilidad por las decisiones que tomaron, aún cuando los dados de la historia estuvieran cargados en esa dirección. 
Marco Iazzetta é Professor da Faculdade de Ciência Politica e RRII da UNR. E Doutor em Ciência Política pela Universidade Nacional de Rosário (UNR) e Doutor em Filosofia pela Universidade de Paris. E-mail: marcoiaz@hotmail.com.

\section{Referências}

ALTAMIRANO, Carlos. Peronismo y Cultura de Izquierda. Buenos Aires: Siglo XXI, 2011.

ARONSKIND, Ricardo. Los modelos armados y la Argentina de los sesenta. In: JELÍN, Elizabeth et al.

(Org.). Lucha Armada en la Argentina. Buenos Aires: Ejercitar la memoria editores, 2011. p. 38-56.

BRENNAN, James P. El Cordobazo. Las guerras obreras en Córdoba. Buenos Aires: Editorial Sudamericana, 1996.

BIOY CASARES, Adolfo. Diario de la Guerra del Cerdo. Buenos Aires: Altaya, 1999.

CARASSAI, Sebastián. Los años setenta de la gente común. La naturalización de la violencia. Buenos Aires: Siglo XXI, 2013.

CAVAROZZI, Marcelo. Autoritarismo y democracia (1955-2006). Buenos Aires: Ariel, 2006.

FERRER, Christian. Camafeos. Sobre algunas figuras excéntricas, desconcertantes o inadaptadas. Buenos Aires: Ediciones Godot, 2013.

GILMAN, Claudia. Entre la pluma y el fusil. Debates y dilemas del escritor revolucionario en América Latina. Buenos Aires: Siglo XXI, 2012.

HILB, Claudia. La responsabilidad como legado. In: TCACH, César. La Politica en Consignas: Memoria de los Setenta. Rosario: Homo Sapiens Ediciones, 2003. p. 101-121.

HILB, Claudia; LUTZKY, Daniel. La Nueva Izquierda Argentina: 191960-1980. Buenos Aires: Centro Editor de América Latina, 1984.

HIRSCHMAN, Albert. Interés Privado y acción pública. México: Fondo de Cultura Económica, 1986.

LONGONI, Ana; MESTMAN, Mariano. Del Di Tella a "Tucumán Arde". Buenos Aires: Eudeba, 2010.

LONGONI, Ana. Vanguardia y revolución. Arte e izquierdas en la Argentina de los sesenta-setenta. Buenos Aires: Ariel, 2014.

LOTERSZTAIN, Israel. Morir por los “cambios de fondo”. In: JELÍN, Elizabeth et al. (Org.). Lucha Armada en la Argentina. Buenos Aires: Ejercitar la memoria editores, 2010. p. 64-68.

JAMESON, Fredric. Periodizar los 1960. Córdoba: Alción, 1997.

O’DONNELL, Guillermo. El Estado burocrático autoritario. Buenos Aires: Editorial Belgrano, 1982.

O’DONNELL, Guillermo. Contrapuntos. Ensayos escogidos sobre autoritarismo y democratización. Buenos Aires: Paidós, 1997.

OLLIER, María Matilde. El Fenómeno insurreccional y la cultura política. Buenos Aires: Centro Editor de América Latina, 1986.

OLLIER, María Matilde. La Creencia y la Pasión: Privado, público y político en la izquierda revolucionaria. Buenos Aires: Compañía Editora Espasa Calpe Argentina S.A./Ariel, 1998. 
184 | Marco Iazzetta

SVAMPA, Maristella. El populismo imposible y sus actores (1973-1976). In: JAMES, Daniel. Violencia, proscripción y autoritarismo. Buenos Aires: Sudamericana, Nueva Historia Argentina Tomo IX, 2007. p. 383-438.

TCACH, César. Prefacio. In: TCACH, César (Comp.). La politica en consignas. Memorias de los setenta. Rosario: Homo Sapiens Ediciones, 2003. p. 11-12.

TERÁN, Oscar. La historia de las ideas en la Argentina. Buenos Aires: Siglo XXI Editores, 2008.

WALDMANN, Peter. Anomia Social y Violencia. In: ROUQUIÉ, Alain (Comp.). Argentina, hoy. Buenos Aires: Siglo XXI, 1982.

WILLIAMS, Raymond. Marxismo y literatura. Barcelona: Península/Biblos, 1997.

Texto recebido em 29 de abril de 2015. Aprovado em 09 de novembro de 2015. 